\title{
Implementation of GINA guidelines in asthma management by primary care physicians in Vietnam
}

\author{
Vinh Nhu Nguyen ${ }^{1-3}$ \\ Quynh Nhat Nguyen ${ }^{2}$ \\ Pham Le $\mathrm{An}^{2}$ \\ Niels H Chavannes' \\ 'Department of Public Health and \\ Primary Care, Leiden University \\ Medical Center, Leiden, the \\ Netherlands; ' ${ }^{2}$ Department of Family \\ Medicine, Faculty of Medicine, \\ University of Medicine and Pharmacy \\ at $\mathrm{Ho}$ Chi Minh City, Vietnam; ${ }^{3}$ Asthma \\ and COPD Clinic, University Medical \\ Center, Ho Chi Minh City, Vietnam
}

Correspondence: Vinh Nhu Nguyen Department of Family Medicine, Faculty of Medicine, University of Medicine and Pharmacy at Ho Chi Minh City, 217 Hong Bang Street, District 5, Ho Chi Minh City 70000, Vietnam

Email vinhnguyenmd@ump.edu.vn
This article was published in the following Dove Press journal:

International Journal of General Medicine

5 October 2017

Number of times this article has been viewed

Background: Asthma control is suboptimal in Vietnam. Lack of knowledge of primary care physicians (PCPs) for asthma management may potentially be one of the causes.

Purpose: The aim of this study was to assess the knowledge and practice of PCPs' asthma management based on the Global Initiative for Asthma (GINA) guidelines (2015 update).

Methods: A cross-sectional study with convenience sampling was conducted among PCPs in an urban and rural area of Vietnam using questionnaires related to asthma patients daily practice: use of spirometry and the asthma control test (ACT), prescription of asthma medications, and frequency of consultations. Five asthma case scenarios were also used to ask participants to classify GINA-defined levels of asthma control and to choose the initial or adjusted treatment options based on the current situation. All scenarios are common in Vietnam, ie, three cases for adults, one case for children, and one case for pregnant women.

Results: Of the 327 completed questionnaires, 201 questionnaires could be analyzed. Most PCPs consulted their asthma patients on a weekly to monthly basis. Approximately $50 \%$ used spirometry for asthma care and only $25 \%$ used ACT. For asthma treatment, oral short-acting beta agonists and oral steroids were still commonly used and long-acting beta agonists alone were prescribed by $70 \%$. Regarding GINA-defined levels of asthma control, $24 \%$ of the responders had $\geq 50 \%$ of correct answers, $21 \%$ had no correct answers, $2 \%$ had all five correct answers, and $20-42 \%$ had a correct answer for each of the five questions. Regarding treatment choice, $22 \%$ had $\geq 50 \%$ of correct answers, $14 \%$ had a wrong answer for all nine questions, and no respondent had a correct answer for $\geq 8$ questions.

Conclusion: The percentage of PCPs in Vietnam who had implemented GINA 2015 was low. Some drugs with a high risk of side effects were still being prescribed. There is a need to improve both knowledge and daily practice. Additional studies should determine why these guidelines are not largely adopted by PCPs in Vietnam.

Keywords: asthma control, asthma treatment, knowledge, practice, case scenarios

\section{Introduction}

Asthma is a major chronic disease among children and adults and remains a significant health problem in Vietnam. ${ }^{1-3}$ The prevalence has been estimated at $3.9-5.6 \%$ of adults aged 21-70 years, ${ }^{4}$ in Ho Chi Minh city (where this study was conducted), the prevalence of "ever asthma" in children aged 6-7 years was $10.9 \%$ and that of wheezing in children aged $13-14$ years was $29.5 \%$, the highest in the Asian-Pacific region. ${ }^{5}$ The prevalence of asthma in Tien Giang, a rural province participating in this study, was $6 \%{ }^{6}$

In Vietnam, the Global Initiative for Asthma (GINA) guidelines has been used since 2009 as the main reference for national asthma guidelines ${ }^{7,8}$ and GINA updated 
2015 was revised to become more practical for primary care where most asthma patients are managed. ${ }^{9}$ Despite the availability of effective evidence-based management strategies, asthma management in Vietnam remains suboptimal. An earlier study reported that the level of asthma control is poorer than expected, ie, $\leq 1 \%$ of patients met the correct definition of controlled asthma. ${ }^{10}$ There could be a variety of reasons for these both health care system related and doctor/ patient related. The majority of the ambulatory care of asthma in Vietnam is provided by primary care physicians (PCPs); however, the use of controller medications (eg, inhaled corticosteroids [ICS]) in this setting is challenge because of their unavailability $^{11}$ and/or unaffordability for patients with a low/ average income. ${ }^{1,2,12-14}$ Apart from this, lack of knowledge on asthma management by health care providers is another factor contributed to this low level of asthma control. It has been shown that knowledge and competence of PCPs are low and vary among countries and with time in the same country, ${ }^{15-19}$ but these could be improved by education. ${ }^{20-24}$

In order to improve asthma management in Vietnam, beside efforts from the health care system to make good resources for asthma care, the gap in knowledge on and practice of asthma management of PCPs need to be assessed and then improved. Therefore, this study aimed to determine their knowledge on and practice of asthma management in Ho Chi Minh City (an urban setting) and Tien Giang province (a rural setting).

\section{Methods}

This was a cross-sectional study with convenience sampling using questionnaires to ask PCPs about asthma care in routine clinical practice in the period October 2015 to October 2016. In Vietnam, PCPs are those who are general practitioners (GPs) (6 years medical doctors [MDs] having no further postgraduate training), ${ }^{25}$ internists (INs) (MDs having postgraduate training in internal medicine), and family physicians (FPs) (MDs having postgraduate training in family medicine). ${ }^{25,26}$ Participants were PCPs who attended the "family medicine training course" in either Tien Giang province or Ho Chi Minh City, or who worked in four district hospitals in Ho Chi Minh City (most of the doctors in outpatient department in district hospitals are PCPs and most of the services in outpatient department in hospitals even tertiary one are primary care services). ${ }^{25}$ The printed questionnaires and informed consent forms were provided to participants in person and were returned after 1-7 days. The study protocol was approved by the Institutional Review Board of the University of Medicine and Pharmacy at Ho Chi Minh City.

The questionnaires comprised two sections. The first section asked how often in routine clinical practice 1) participants saw their asthma patients, 2) the tools they used (spirometry and asthma control test (ACT), which was validated in Vietnamese version), ${ }^{27}$ and 3) the asthma medications prescribed. The second section, based on the five case scenarios, asked participants about the GINA-defined classification of asthma control and the GINA-recommended asthma treatments. These case scenarios were developed from literature (eg, a case study by Ko et $\mathrm{al}^{28}$ performed in Hong Kong) and Vietnamese expert consensus (four specialists: two specialists in primary care and two specialists in asthma/COPD) on the content validity (common practice cases) and time cost. The matrix of asthma information need to be assessed was developed in Table 1 in which each of the five cases presented characteristics that are very clear for the classification of asthma control as recommended by GINA 2015. ${ }^{29}$ Three adult scenarios help to assess uncontrolled, partly controlled, and controlled asthma. These are very common cases that require the ability of physicians to start treatment and modify the treatment when required. The other two cases are uncontrolled asthma in children and partly controlled asthma in pregnant women. These cases are also common in Vietnam, where the prevalence of asthma in children is higher than in adults, and the prevalence in

Table I Framework of evaluation of knowledge and treatment strategy based on the GINA 20 I5 guidelines

\begin{tabular}{lll}
\hline & Questions related to: & Initial treatment \\
\cline { 2 - 3 } & Assessment of level of control & $\times$ \\
\hline Case I: adult with partly controlled asthma & $\times$ & $\times$ \\
Case 2: adult with uncontrolled asthma & $\times$ & $\times$ \\
Case 3: adult with controlled asthma & $\times$ & $\times$ \\
Case 4: children with uncontrolled asthma & $\times$ & $\times$ \\
Case 5: pregnant woman with partly controlled asthma & $\times$ & \\
\hline
\end{tabular}

Abbreviation: GINA, Global Initiative for Asthma. 
pregnant women remains high (fertility rate is 1.96 children born/woman in the year 2015). ${ }^{30}$ To avoid that participants spent too much time filling in questionnaires, in the last two scenarios, only one question on treatment was asked (Table 1: case 4 and case 5). A total of five questions enquired about the GINA-defined assessment of asthma control and nine questions enquired about asthma treatment (ie, three questions on initial treatment and six questions on adjusted treatment; Supplementary material). Table 1 shows the matrix of information need to be assessed in the five case scenarios. The questionnaires and cases were then tested in 10 FPs in our Department of Family Medicine (University of Medicine and Pharmacy at Ho Chi Minh City) and then provided to participants without modification.

For all treatment questions, the correct answer was based on the GINA 2015 guidelines (Supplementary material: shaded options) and was defined as having no incorrect choice and having at least one correct choice. In the analyses, the correct answer scored 1 point and the wrong answer scored 0 points.

Data were processed using the Microsoft Excel 2007 software and analyzed using the STATA 12.0 software (copyright from Public Health Department, University of Medicine and Pharmacy). Ratio variables are presented as mean and standard deviation (SD). Student's $t$-test was used to compare the means of two groups, and one-way ANOVA was used to compare the means of multiple groups. A $P$-value of $\leq 0.05$ was considered statistically significant.

\section{Results}

A total of 350 questionnaires were distributed. Of the 327 questionnaires that were filled in and returned, 80 responders did not report their specialty and 46 responders belonged to a specialty other than GP, IN, or FP. In Vietnam, many specialists provided primary care services at their own private clinics in extra time (out of office time) explained why many specialists attended to a family medicine training course. ${ }^{31,32}$ Therefore, only 201 answer sheets satisfied the requirement of an appropriate specialty for the present analysis (18\% FPs and $82 \%$ being a combination of GPs and INs).

Of these 201 respondents, 71\% were from rural Tien Giang and 29\% were from Ho Chi Minh City; their mean age was 47 (SD 9; range 24-82) years and the mean length of time as practitioner was 15 (SD 9; range $1-48$ ) years. Table 2 presents the characteristics of the respondents.

Table 3 presents information on the use of spirometry and ACT and the frequency of seeing asthma patients and of prescribing medications. Most physicians saw their patients
Table 2 Characteristics of the study participants $(n=201)$

\begin{tabular}{ll}
\hline Characteristic & n (\%) \\
\hline Province & \\
Ho Chi Minh City & $58(29)$ \\
Tien Giang & $143(7 \mathrm{I})$ \\
Specialty & \\
$\quad$ General practitioners/internists & $164(82)$ \\
Family physicians & $37(18)$ \\
Gender & \\
Male & $86(46)$ \\
Female & $102(54)$ \\
Age group (years) & \\
$24-40$ & $37(18.4)$ \\
$4 I-50$ & $78(38.8)$ \\
$>50$ & $86(42.8)$ \\
Years of practice & \\
I-10 & $87(43)$ \\
II-20 & $53(26)$ \\
$>20$ & $57(28)$ \\
Unknown & $4(2)$ \\
\hline
\end{tabular}

Table 3 Use of spirometry and ACT and frequency of consultations and prescribing medication in asthma care

\begin{tabular}{ll}
\hline & $\mathbf{n}(\%)$ \\
\hline Use of spirometry in practice & $100(49.8)$ \\
Yes & $83(41.3)$ \\
No & $18(9)$ \\
No answer & \\
Use of asthma control test in practice & $49(24.4)$ \\
Yes & $115(57.2)$ \\
No & $37(18.4)$ \\
No answer & \\
Frequency of seeing asthma patients & $17(8.5)$ \\
Daily & $65(32.3)$ \\
Weekly & $47(23.4)$ \\
Monthly & $62(30.8)$ \\
Few times per year & $10(5.0)$ \\
Unanswered & \\
Frequency of prescribing asthma medications & $15(7.5)$ \\
Daily & $58(28.9)$ \\
Weekly & $49(24.4)$ \\
Monthly & $59(29.4$ \\
Few times per year & $20(10)$ \\
Unanswered &
\end{tabular}

Abbreviation: $\mathrm{ACT}$, asthma control test.

once a week, but some prescribed asthma medication only a few times per year.

Table 4 lists the types of medications prescribed in relation to the numbers of patients; $70 \%$ of the respondents used a long-acting beta agonist (LABA) alone for asthma treatment.

Based on the five case scenarios, Table 5 presents the percentages of respondents who correctly/incorrectly assessed the asthma control levels according to the GINA 2015 guidelines: $16-23 \%$ of the respondents failed to give answer to one 
of the five questions and three physicians chose to respond with "no answer/unknown" to all five case scenarios.

The section on choice of asthma treatment/management was divided into 1) initial treatment and 2) adjusted treatment, based on the five scenarios. Table 6 presents the percentages of correct/incorrect responses. These questions on treatment had fewer "unanswered" responses compared to the questions on classification of asthma control.

In GINA stepwise treatment, decision making for initial treatment is based on the frequency of symptoms, risk of exacerbation, and level of asthma control (GINA 2015, Box 3-4, page 30). ${ }^{33}$ The GINA recommended step 2 for

Table 4 Asthma medications prescribed to patients in practice

\begin{tabular}{|c|c|c|c|c|c|c|}
\hline Asthma medication & Not prescribed & A few patients & Some patients & Most patients & All patients & Unanswered \\
\hline \multicolumn{7}{|l|}{ Oral medications } \\
\hline Oral SABA & $25(12.4)$ & $43(21.4)$ & $48(23.9)$ & $45(22.4)$ & $7(3.5)$ & $33(16.4)$ \\
\hline Oral steroid & $9(4.5)$ & $47(23.4)$ & $68(33.8)$ & $46(22.9)$ & $6(3)$ & $25(12.4)$ \\
\hline Oral theophylline & $50(24.9)$ & $48(23.9)$ & $48(23.9)$ & $23(11.4)$ & $0(0)$ & $32(15.9)$ \\
\hline Antileukotriene & $52(25.9)$ & $32(15.9)$ & $45(22.4)$ & $20(10)$ & $4(2.0)$ & $48(23.9)$ \\
\hline Mucolytic & $12(6)$ & $44(21.9)$ & $53(26.4)$ & $49(24.9)$ & $14(7)$ & $29(14.4)$ \\
\hline \multicolumn{7}{|l|}{ Inhaler medications } \\
\hline ICS & $17(8.5)$ & $35(17.4)$ & $52(25.9)$ & $59(29.4)$ & $16(8)$ & $22(10.9)$ \\
\hline Inhaled SABA & $18(9)$ & $27(13.4)$ & $66(32.8)$ & $58(28.9)$ & II (5.5) & $21(10.4)$ \\
\hline Inhaled ICS + LABA & $31(15.4)$ & $34(16.9)$ & $56(27.9)$ & $34(16.9)$ & $14(7)$ & $32(15.9)$ \\
\hline Inhaled anticholinergic & $47(23.4)$ & $35(17.4)$ & $50(24.9)$ & $17(8.5)$ & $10(5)$ & $42(20.9)$ \\
\hline \multicolumn{7}{|l|}{ Oral or inhaler medications } \\
\hline LABA (inhaler or oral) & $28(13.9)$ & $31(15.4)$ & $63(31.3)$ & $36(17.9)$ & $10(5)$ & $33(16.4)$ \\
\hline
\end{tabular}

Note: Data presented as $\mathrm{n}(\%)$.

Abbreviations: ICS, inhaled corticosteroid; LABA, long-acting beta agonist; SABA, short-acting beta agonist.

Table 5 Results of assessment of asthma control based on the five case scenarios

\begin{tabular}{llll}
\hline Case scenario & Correct, $\mathbf{n}(\%)$ & Incorrect, $\mathbf{n}(\%)$ & No answer/unknown, $\mathbf{n}(\%)$ \\
\hline Case I: adult, partly controlled asthma & $43(2 \mathrm{I})$ & $\mathrm{II}(59)$ & $39(19)$ \\
Case 2: adult, uncontrolled asthma & $77(38)$ & $9 \mathrm{I}(45)$ & $33(16)$ \\
Case 3: adult, controlled asthma & $84(42)$ & $83(4 \mathrm{I})$ & $34(17)$ \\
Case 4: children, uncontrolled asthma & $83(4 \mathrm{I})$ & $7 \mathrm{I}(35)$ & $47(23)$ \\
Case 5: pregnant woman, partly controlled asthma & $40(20)$ & $123(6 \mathrm{I})$ & $38(19)$ \\
\hline
\end{tabular}

Table 6 Choice of initial and adjusted treatment of participants based on five case scenarios

\begin{tabular}{|c|c|c|c|}
\hline Treatment & Correct, n (\%) & Incorrect, n (\%) & $\begin{array}{l}\text { No answerl } \\
\text { unknown, } \mathrm{n}(\%)\end{array}$ \\
\hline \multicolumn{4}{|l|}{ Initial treatment } \\
\hline Case I: question IB: start treatment for adult with partly controlled asthma & $45(22.4)$ & $156(77.6)$ & $0(0)$ \\
\hline Case 2: question 2B: start treatment for adult with uncontrolled asthma & $102(50.7)$ & $98(48.8)$ & $\mathrm{I}(0.5)$ \\
\hline Case 4: question 4B: start treatment for children with uncontrolled asthma & $106(52.7)$ & $90(44.8)$ & $5(2.5)$ \\
\hline \multicolumn{4}{|l|}{ Adjusted treatment } \\
\hline $\begin{array}{l}\text { Case I: question IC: adjust treatment for adult with partly controlled asthma on } \\
\text { low-dose ICS }\end{array}$ & $58(28.9)$ & $137(68.2)$ & $6(3)$ \\
\hline $\begin{array}{l}\text { Case 2: question 2C: adjust treatment for adult with uncontrolled asthma on I } \\
\text { ow-dose ICS }\end{array}$ & $97(48.3)$ & $96(47)$. & $8(4)$ \\
\hline $\begin{array}{l}\text { Case 2: question 2D: adjust treatment for adult with uncontrolled asthma on a } \\
\text { combination ICS/LABA }\end{array}$ & $43(21.4)$ & $154(76.6)$ & $4(2)$ \\
\hline $\begin{array}{l}\text { Case 3: question 3B: adjust treatment for adult with controlled asthma on } \\
\text { low-dose ICS }\end{array}$ & $47(23.4)$ & $152(75.6)$ & $2(1)$ \\
\hline $\begin{array}{l}\text { Case 3: question 3C: adjust treatment for adult with controlled asthma on } \\
\text { combination ICS/LABA }\end{array}$ & $52(25.9)$ & $|4|(70.1)$ & $8(4)$ \\
\hline $\begin{array}{l}\text { Case 5: question 5B: adjust treatment for pregnant woman with partly controlled } \\
\text { asthma on low-dose ICS }\end{array}$ & 24 (11.9) & $173(86)$ & $6(3)$ \\
\hline
\end{tabular}

Abbreviations:; ICS, inhaled corticosteroid; LABA, long-acting beta agonist. 
steroid-naive patients with uncontrolled (uncontrolled or partly controlled) asthma or step 3 for those still not controlled on steroids or for steroid-naive patients with uncontrolled asthma and nocturnal awakening due to asthma once a week or more. ${ }^{33}$ Therefore, the correct initial treatment for case 1 (partly controlled asthma, question 1B) is step 2, for case 2 (uncontrolled asthma with nocturnal symptoms once a week, question $2 \mathrm{~B}$ ) is step 2 or step 3, and for case 4 (uncontrolled asthma with nocturnal symptoms once a week, question 4B) is step 2 or step 3.

Figure 1 presents the distribution of the scores on asthma control/asthma treatment, as well as the combined (questions on asthma control and treatment) total score. Only two participants (one GP/IN and one FP) correctly answered all five questions, whereas $21 \%$ either did not know how to classify or incorrectly assessed asthma control in all five questions (Figure 1A). Also, 24\% of the responders had $\geq 50 \%$ of correct answers (ie, $\geq 3$ correct answers out of the five questions).

Moreover, for all nine treatment questions, $14 \%$ of the physicians had no correct answer to any of these questions and no respondent had eight or nine correct answers. A total of 44 physicians $(22 \%)$ had $\geq 50 \%$ of correct answers $(\geq 5 / 9)$; most of these were GPs or INs (Figure 1B). Most FPs (95\%) also had $\leq 50 \%$ of correct answers. In terms of the total 14 questions related to the case scenarios, only $21 \%$ of the participants had $\geq 50 \%(\geq 7 / 14)$ of correct answers (Figure $1 \mathrm{C})$.

A comparison was made of the mean scores of the results of 1) GPs/INs vs FPs, 2) city (Ho Chi Minh) vs rural province (Tien Giang), and 3) groups based on age and years of experience as a practitioner. Table 7 presents differences in the mean scores in categories related to all 14 questions.

For asthma control classification, there was no difference in mean score among doctors with different age groups, years of experience, residential areas, and specialties. However, with both initial choice and adjustment in treatment decision, the younger group had less mean score than that of older one; doctors in Tien Giang province decided better than those in Ho Chi Minh City did, and GPs/INs had better mean score than FPs had. Years of experience seem not to associate with both asthma control classification and treatment choices.

\section{Discussion}

The main finding of this study is that only one-fifth (24\%) of the participants had $\geq 50 \%$ of correct answers in the classification of GINA-defined asthma control and the same proportion of doctors ( $22 \%$ ) had $\geq 50 \%$ of correct answers in treatment decision. These numbers are low, and also knowledge on asthma about control criteria and stepwise treatment in PCPs is low worldwide. ${ }^{16,22,34-43}$

In terms of asthma control, $49 \%$ of PCPs in the present study used ACT in routine practice and $21 \%$ did not know how to classify asthma control level (having 0 correct answers) based on GINA guidelines. With the questions on "controlled" and "uncontrolled" asthma classification, the correct answer is $38-42 \%$, but with the questions on "partly controlled" asthma, the correct answer is lower (20-21\%) (Table 5). Our results are comparable to some previous reports. Braido et $\mathrm{al}^{29}$ found that only $20 \%$ of the GPs in their study in Italy were able to correctly answer questions on asthma control. In a recent survey of doctors working in family and internal medicine practices in Nigeria, the authors found that only $30 \%$ of physicians had good or satisfactory knowledge on asthma control tools in which only $15 \%$ of them used GINA-defined control, 5.2\% used ACT, and 74.2\% of the doctors were unaware of the level of asthma control as the basis for treatment. ${ }^{43}$ Even in a tertiary hospital in Nigeria, only $31 \%$ of doctors (INs, PFs, and pulmonologists) and 55\% of pulmonologists knew correctly about the asthma control
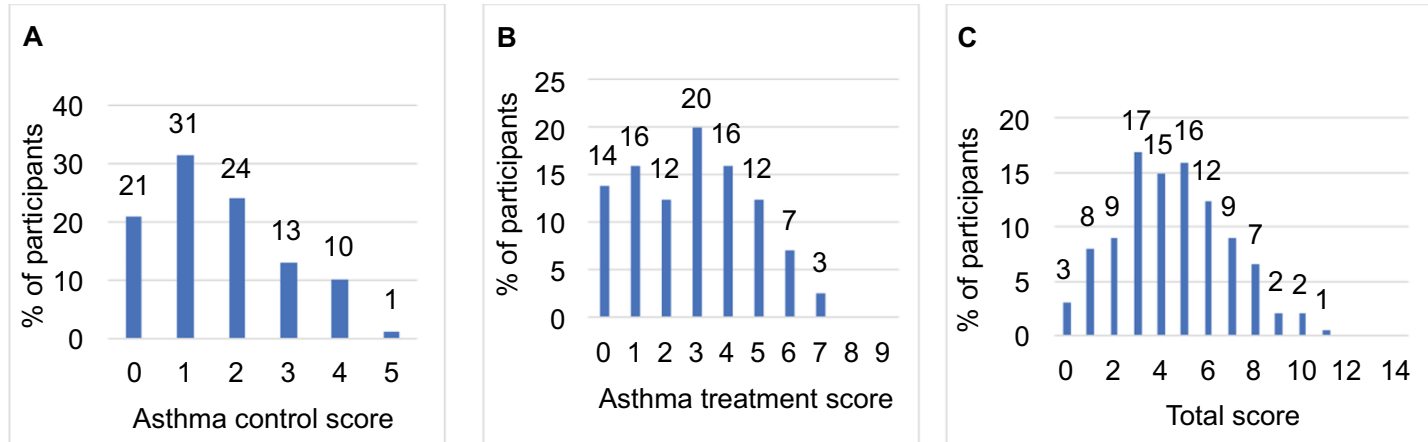

Figure I Distribution of correct answers in asthma control and asthma treatment and the combined total score.

Notes: (A) Distribution of correct answers to the five questions on classification of asthma control; (B) distribution of correct answers to the nine asthma treatment questions; and $(\mathbf{C})$ distribution of correct answers to all 14 questions related to the five case scenarios. 
classification. ${ }^{34}$ Similarly, a limited level of knowledge on asthma control criteria was demonstrated among PCPs in the Republic of Moldova and only $41 \%$ of doctors there used ACT in daily practice. ${ }^{44}$ Compared to the study with the same format by Ko et al, ${ }^{28}$ our correct assessment rate was lower, ie, only $24 \%$ of our respondents had $\geq 50 \%$ of correct answers related to asthma control vs $\geq 90 \%$ of respondents in their study. However, Ko et al, combined partly controlled and uncontrolled questions into one (choice of) answer, ${ }^{28}$ giving their respondents a higher chance of having a correct answer than when these questions are separated (as in our study). If we had used the same combination as in Ko et al, ${ }^{28}$ then the number of correct answers in our study would have been significantly increased.

In asthma management, the GINA guidelines recommended five treatment steps and provide a guide to starting initial treatment and adjustment, depending on the patient's current situation. However, it is very difficult to follow the guidelines in primary care sector in many countries. There were $37.2 \%$ PCPs in Kuwait, 33.7\% were adhering to asthma guidelines in Saudi Arabia, ${ }^{15,16}$ and even in tertiary hospital in Nigeria, physicians (including INs, PFs, and pulmonologists) could only correctly identify appropriate management strategies in $36 \%$ of the cases. ${ }^{34}$ In addition, the number of PCPs who had adequate knowledge practice in asthma management in a study in Pakistan is very low as $10.4 \%{ }^{36}$ With asthma treatment in general (both starting and adjustment), the percentage of physicians who achieved $\geq 50 \%$ of correct answers ( $\geq 5 / 9)$ for all nine questions on treatment in our study is $22 \%$ (Figure 1B); this is roughly similar to that in the same format study in Hong Kong (32\%). ${ }^{28}$

In this study, $>50 \%$ of participants selected correct initial treatment for uncontrolled asthma patients, only $22.4 \%$ did the same for partly controlled asthma patients (Table 6), and the most preferred option for initial treatment is ICS. Compared to other studies, the proportion of PCPs who knew and had proper prescription of corticosteroids for asthma is low as $1.7-6.6 \%$ in Nigeria, ${ }^{40,45} 18.2 \%$ in India, ${ }^{19} 27 \%$ in Moldova, ${ }^{44}$ and $33 \%$ in Pakistan. ${ }^{46}$ These low numbers may be due to ICS, which is not always available in primary care sector in most of the developing countries. ${ }^{11}$

Regarding the adjusted treatment, $46.8 \%$ of respondents in this study correctly adjusted medication for uncontrolled patients on low-dose ICS (question 2C) to a combination of ICS and LABA (Supplementary material) as GINA recommendations. This number is quite high compared to the results from a study from Nigeria in which only $29 \%$ reported prescribing a combined ICS and LABA for their patients who 
are not controlled on inhaled steroid alone. ${ }^{47}$ However, in our controlled asthma case, instead of maintaining the same treatment step or stepping down, most of our respondents chose to step-up (Supplementary material: responses to questions 3B and $3 \mathrm{C}$ ). This may be due to the misclassification of asthma control in this specific case, ie, $\geq 50 \%$ of respondents made an incorrect classification. Therefore, we propose that training courses should include case presentations because it could provide to learners a continuous story that can fill in the gap of knowledge of our PCPs.

In our study, although there were no very severe asthma cases, a few physicians still select oral medications, eg, short-acting beta agonist (SABA) and steroids (Supplementary material). Table 4 shows that $\geq 20 \%$ of respondents still prescribe oral SABA/steroids for most/all of their patients in daily practice. Also, despite that the use of a LABA alone is prohibited in asthma management, $22.9 \%$ of physicians prescribed this medication for most or all of their patients (Table 4). Oral theophylline was recommended in the GINA guidelines for step 2 or as add-on in step 3 treatment; however, fewer physicians prescribed theophylline than oral SABA, oral steroids, or even LABA. Moreover, although guidelines recommend that plasma theophylline concentrations should be monitored during use, in Vietnam, very few locations are able to perform such monitoring. This may be a reason for the scarce use of theophylline in Vietnam.

Treatment of asthma in pregnant women is often difficult for PCPs due to the lack of this issue in our training program in Vietnam; accordingly, in this study, the number of respondents correctly selecting the adjusted treatment for pregnant women was very low (11.9\%; Table 6). For this question (question 5B), most physicians chose the response "no change in treatment" for patients with daily use of SABA and categorized as partly controlled asthma based on the GINA guidelines. This answer, together with the answer to question 1B, seems to imply that most of the PCPs in Vietnam considered partly controlled asthma to be acceptable, with no need to change the therapy.

The present study also investigated whether a difference exists in asthma management among respondents of different ages, years of experience, locations, and specialties. Differences were found for all these parameters but not for years of experience (Table 7). In some study, authors found that more years of experience led to better knowledge of asthma; ${ }^{16}$ however, this judgment is not consistent. ${ }^{15,19}$ Knowledge concerning the assessment of asthma control was the same in all groups, whereas a significant difference was found between groups regarding knowledge of asthma treatment (both initiating treatment and adjusting treatment). In contrast to the Hong Kong study (in which older respondents had the lowest level of knowledge on asthma treatment), ${ }^{28}$ in the present study, our youngest age group (24-40 years) scored the lowest in selecting appropriate treatment for asthma patients. Also, mean scores of asthma treatment in respondents from the urban environment was less than those from the rural province. This implies that even PCPs in the most modern city in Vietnam (where many conferences and continuing medical education (CME) of asthma/COPD take place) were not familiar with the GINA 2015 guidelines. Although the performance of the GPs/INs in this study was better than that of the FPs, this result needs further investigation because there were fewer FPs in this study than GPs or INs. A study in Kuwait revealed that there was no difference in the performance of GPs and FPs. ${ }^{15}$

A limitation of this study is that, because the population sample was not randomly selected, it may not be fully representative of PCPs in Ho Chi Minh City and in Tien Giang province.

\section{Conclusion}

This study shows that the percentage of PCPs complying the (updated) GINA 2015 guideline in Vietnam was low. Many physicians may not familiar with the GINA classification of asthma control; moreover, drugs known to have a high risk of side effects were still being used. There is a need to improve knowledge and change practice, either via $\mathrm{CME}$ programs or by targeted use of health care resources. Meanwhile, additional studies are required to determine why the updated GINA 2015 guidelines are not extensively adhered to primary care in Vietnam.

\section{Authors' contributions}

VNN, QNN, and PLA conducted the study. VNN and PLA analyzed the data. VNN drafted the manuscript. NHC edited the manuscript. All authors have reviewed the manuscript. All authors contributed toward data analysis, drafting, and revising the paper and agree to be accountable for all aspects of the work.

\section{Disclosure}

The authors report no conflicts of interest in this work.

\section{References}

1. Nguyen TT, Nguyen NB. Economic burden of asthma in Vietnam: an analysis from patients' perspective. Value Health. 2014;17(7):A627.

2. Nguyen NBT, Nguyen TTT. Incidence-based cost of asthma in Vietnam. Value Health. 2014;17(7):A777-A778.

3. Asthma in Vietnam [webpage on the Internet]. Statistics on Overall Impact and Specific Effect on Demographic Groups. Available from: http://global-disease-burden.healthgrove.com/1/48342/Asthma-inVietnam. Accessed September 5, 2017. 
4. Lam HT, Ronmark E, Tu'o'ng NV, Ekerljung L, Chuc NT, Lundback B. Increase in asthma and a high prevalence of bronchitis: results from a population study among adults in urban and rural Vietnam. Respir Med. 2011;105(2):177-185.

5. Lai CK, Beasley R, Crane J, et al. Global variation in the prevalence and severity of asthma symptoms: phase three of the International Study of Asthma and Allergies in Childhood (ISAAC). Thorax. 2009;64(6): 476-483.

6. Tram TV. Asthma at Tien Giang province. Ho Chi Minh City Med J. 2011;15(4).

7. Ministry of Health. Vietnamese Asthma Management Guidelines. Order 4776/QD-BYT Date 04/12/2009. Ministry of Health; 2009.

8. Viet Nam Association against Tuberculosis and Lung Diseases. Viet Nam Guidelines for Asthma and Chronic Obstructive Pulmonary Disease Management. Viet Nam Association against Tuberculosis and Lung Diseases; 2015.

9. Reddel HK, Levy ML; Global Initiative for Asthma Scientific C. Dissemination, implementation C. The GINA asthma strategy report: what's new for primary care? NPJ Prim Care Respir Med. 2015;25:15050.

10. Lai CK, De Guia TS, Kim YY, et al. Asthma control in the Asia-Pacific region: the Asthma Insights and Reality in Asia-Pacific Study. JAllergy Clin Immunol. 2003;111(2):263-268.

11. The International Union Against Tuberculosis and Lung Disease. The Global Asthma Report 2011. Paris, France: The International Union Against Tuberculosis and Lung Disease; 2011.

12. Ait-Khaled N, Auregan G, Bencharif N, et al. Affordability of inhaled corticosteroids as a potential barrier to treatment of asthma in some developing countries. Int J Tuberc Lung Dis. 2000;4(3):268-271.

13. Nguyen AT, Knight R, Mant A, Cao QM, Auton M. Medicine prices, availability, and affordability in Vietnam. South Med Rev. 2009;2(2):2-9.

14. Lai CKW, Kim YY, Kuo SH, Spencer M, Williams AE. Cost of asthma in the Asia-Pacific region. Eur Respir Rev. 2006;15(98):10-16.

15. Almutawa FN, Al-Mutairy G, Al-Arada N, Kamel MI. Perception of primary care physicians about guidelines of bronchial asthma. Alexandria J Med. 2014;50(1):17-24.

16. Yousef HA, Koura M, Yousef AA. Knowledge about bronchial asthma management in primary health care physicians in Al-Khobar City, Saudi Arabia. J Family Commun Med. 2015;22(1):1-7.

17. Levy ML. Guideline-defined asthma control: a challenge for primary care. Eur Respir J. 2008;31(2):229-231.

18. Ingemansson M, Wettermark B, Jonsson EW, et al. Adherence to guidelines for drug treatment of asthma in children: potential for improvement in Swedish primary care. Qual Prim Care. 2012;20(2):131-139.

19. Shahid S, Bhinder G, Dhanjal J. Knowledge, attitudes and practices (KAP) of primary care physicians of Central Mumbai Suburbs about childhood asthma. Internet J Asthma Allergy Immunol. 2006;6(1).

20. Haahtela T, Tuomisto LE, Pietinalho A, et al. A 10 year asthma programme in Finland: major change for the better. Thorax. 2006;61(8): 663-670.

21. Haahtela T, Laitinen LA. Asthma programme in Finland 1994-2004. Report of a Working Group. Clin Exp Allergy. 1996;26(suppl 1):i-ii, $1-24$.

22. Rovithis E, Lionis C, Schiza SE, et al. Assessing the knowledge of bronchial asthma among primary health care physicians in Crete: a pre- and post-test following an educational course. BMC Med Educ. 2001;1(1):2.

23. Veninga CCM, ØV PL, WahlstrÖM R, et al. Evaluating an educational intervention to improve the treatment of asthma in four European countries. Am J Respir Crit Care Med. 1999;160(4):1254-1262.

24. Al-Haddad N, Al-Ansari SS, Al-Shari AT. Impact of Asthma Education Program on asthma knowledge of general practitioners. Ann Saudi Med. 1997;17(5):550-552.

25. Fan AP, Tran DT, Kosik RO, Mandell GA, Hsu HS, Chen YS. Medical education in Vietnam. Med Teach. 2012;34(2):103-107.

26. Montegut AJ, Schirmer J, Cartwright C, et al. Creation of postgraduate training programs for family medicine in Vietnam. Fam Med. 2007;39(9):634-638.
27. Nguyen VN, Chavannes N, Le LT, Price D. The Asthma Control Test (ACT) as an alternative tool to Global Initiative for Asthma (GINA) guideline criteria for assessing asthma control in Vietnamese outpatients. Prim Care Respir J. 2012;21(1):85-89.

28. Ko FW, Chan AM, Chan HS, et al. Are Hong Kong doctors following the Global Initiative for Asthma guidelines: a questionnaire "Survey on Asthma Management"? Hong Kong Med J. 2010;16(2):86-93.

29. Braido F, Baiardini I, Stagi E, Piroddi MG, Balestracci S, Canonica GW. Unsatisfactory asthma control: astonishing evidence from general practitioners and respiratory medicine specialists. J Investig Allergol Clin Immunol. 2010;20(1):9-12.

30. World Bank [webpage on the Internet]. Fertility Rate, Total (Births Per Woman). 2017. Available from: https://data.worldbank.org/indicator/ SP.DYN.TFRT.IN?locations=VN. Accessed September 5, 2017.

31. Biinform [webpage on the Internet]. Vietnam Healthcare Report 2012. 2017. Available from https://biinform.com/Reports/11D-vietnamhealthcare-report-2012-4530.html. Accessed September 5, 2017.

32. Lonnroth K, Thuong LM, Linh PD, Diwan V. Risks and benefits of private health care: exploring physicians' views on private health care in Ho Chi Minh City, Vietnam. Health Policy. 1998;45(2):81-97.

33. Global Initiative for Asthma [homepage on the Internet]. Global Strategy for Asthma Management and Prevention. 2015:42. Available from: www.ginasthma.org. Accessed September 5, 2017.

34. Umoh V, Ukpe I. Knowledge of the asthma guidelines among doctors in a tertiary hospital in Nigeria. Ind J Allergy Asthma Immunol. 2012;26(2):77.

35. Vieira JE, Cukier A, Stelmach R, Kasahara DI, Gannam S, Warth M. Comparison of knowledge on asthma: doctors completing internal medicine residency and doctors completing medical school. Sao Paulo Med J. 2001;119:101-104.

36. Bhulani N, Lalani S, Ahmed A, et al. Knowledge of asthma management by general practitioners in Karachi, Pakistan: comparison with international guidelines. Prim Care Respir J. 2011;20:448.

37. Fawibe AE, Joseph KJ, Olaosebikan OF. Evaluation of knowledge of drug treatment of asthma among general practitioners in North Central Nigeria. Chest. 2010;138(4):149A.

38. Erhabor GE, Obaseki DO, Oladimeji O, Soyinka A, Awopeju OF. Knowledge of asthma and its management among newly qualified doctors in South West Nigeria. Chest. 2008;134(4):7.

39. Coates JR, Steven ID, Beilby J, Coffey G, Litt JC, Wagner C. Knowledge of and reported asthma management among South Australian general practitioners. Br J Gen Pract. 1994;44(380):123-126.

40. Obumneme-Anyim IN, Oguonu T, Ayuk AC, Iloh KK, Ndu IK. Knowledge of asthma among doctors practicing in three south eastern states of Nigeria. Ann Med Health Sci Res. 2014;4(suppl 3):S253-S258.

41. Hesse IF. Knowledge of asthma and its management in newly qualified doctors in Accra, Ghana. Respir Med. 1995;89(1):35-39.

42. Taha AZ, Sabr AA, Al Hamed JH. Knowledge about childhood bronchial asthma among primary health care personnel in eastern Saudi Arabia. Int J Med Public Health. 2014;4(3):222-226.

43. Desalu OO, Onyedum CC, Adeoti AO, Ozoh OB, Fadare JO. Knowledge and use of asthma control measurement tools in the management of asthma: a survey of doctors working in family and internal medicine practice in Nigeria. Afr Health Sci. 2016;16(2):480-489.

44. Corlateanu A, Botnaru V, Cemirtan S, Cornei E. A survey of the perception of asthma by primary care physicians in Republic of Moldova. Eur Respir J. 2014;44(suppl):58.

45. Fawibe AE, Onyedum CC, Sogaolu OM, Ajayi AO, Fasae AJ. Drug prescription pattern for asthma among nigerian doctors in general practice: a cross-sectional survey. Ann Thorac Med. 2012;7(2): $78-83$.

46. Hussain SF, Zahid S, Khan JA, Haqqee R. Asthma management by general practitioners in Pakistan. Int J Tuberc Lung Dis. 2004;8(4):414- 417.

47. Adeniyi B, Ilesanmi O, Obaseki D, Desalu O, Betiku B, Erhabor G. Relationship between knowledge and quality of asthma care among physicians in South-West Nigeria. Niger J Clin Pract. 2017;20(5): 566-572. 
The International Journal of General Medicine is an international, peer-reviewed open-access journal that focuses on general and internal medicine, pathogenesis, epidemiology, diagnosis, monitoring and treatment protocols. The journal is characterized by the rapid reporting of reviews, original research and clinical studies across all disease areas.
The manuscript management system is completely online and includes a very quick and fair peer-review system, which is all easy to use. Visit http://www.dovepress.com/testimonials.php to read real quotes from published authors. 